\title{
Correction to: Mental Health, Mental Illness and Migration
}

Driss Moussaoui, Dinesh Bhugra, Rachel Tribe, and Antonio Ventriglio

\section{Correction to: Mental Health, Mental Illness and Migration, D. Moussaoui et al. (eds.), Mental Health, Mental IIIness and Migration, Mental Health and Illness Worldwide, https://doi.org/10.1007/978-981-10-2366-8}

The handbook was inadvertently published with an incorrect spelling of the author's name in Chapters 1, 4, 39, 41, 9, 15 as Antonio V. Ventriglio whereas it should be Antonio Ventriglio.

In addition to this, he is also one of the editors and therefore, his name has now been amended throughout the book as Antonio Ventriglio. \footnotetext{
https://doi.org/10.1007/978-981-10-2366-8_1

https://doi.org/10.1007/978-981-10-2366-8_4

https://doi.org/10.1007/978-981-10-2366-8_39

https://doi.org/10.1007/978-981-10-2366-8_41

https://doi.org/10.1007/978-981-10-2366-8_9

https://doi.org/10.1007/978-981-10-2366-8_15
}

The updated online versions of the chapters can be found at

(C) Springer Science+Business Media Singapore Pte Ltd. 2021

C1

D. Moussaoui et al. (eds.), Mental Health, Mental Illness and Migration,

Mental Health and Illness Worldwide, https://doi.org/10.1007/978-981-10-2366-8_45 